\title{
BIOEQUIVALENCE EVALUATION OF ORALLY DISINTEGRATING STRIPS OF RIZATRIPTAN IN MALE VOLUNTEERS UNDER FASTING CONDITIONS
}

\author{
NIDHI SAPKAL ${ }^{1,2}$, ANWAR DAUD ${ }^{2}$, MINAL BONDE², MANGESH GAWANDE², NILAMBARI GURAV ${ }^{*}$
}

${ }^{1}$ Gurunanak College of Pharmacy, Kamptee Road, Nagpur, Maharashtra, India 440026, 2Zim Laboratories Limited, Kalmeshwar, Nagpur, Maharashtra, India 441501, 3*P. E. S.'s Rajaram and Tarabai Bandekar College of Pharmacy, Goa, India 403401

Email: nilagurav@rediffmail.com

Received: 25 Mar 2021, Revised and Accepted: 29 Jul 2021

\section{ABSTRACT}

Objective: A randomized, open-label, balanced, two-treatment, two-period, two-sequence, single-dose, crossover bioequivalence study comparing Rizatriptan $10 \mathrm{mg}$ Orally Disintegrating Strips (ODS, test) with that of established Oral Lyophilisate Rizatriptan 10 mg, Maxalt-MLT® (reference) was conducted in 24 healthy male volunteers under fasting conditions. A single oral dose of $10 \mathrm{mg}$ Rizatriptan was administrated to each volunteer.

Methods: Plasma concentrations of Rizatriptan were determined by a validated LC-MS/MS bioanalytical method. The plasma concentrations of Rizatriptan were considered for statistical analysis and for establishing bioequivalence. Pharmacokinetic analysis was done by using the noncompartmental method. Pharmacokinetic parameters $C_{\max }, \mathrm{AUC}_{0 \rightarrow \mathrm{t}}, \mathrm{AUC}_{0 \rightarrow \infty}, \mathrm{t}_{1 / 2}, \mathrm{~T}_{\max }$ and Ke1 were estimated for each subject and each treatment.

Results: Ninety percent confidence intervals $(90 \% \mathrm{CI})$ calculated for the ratio of $\mathrm{AUC}_{0 \rightarrow \mathrm{t}}, \mathrm{AUC}_{0 \rightarrow \infty}$, and $\mathrm{C}_{\max }$ values for the test and reference formulations were $96.91-110.30 \%, 96.24-109.07 \%$, and $90.37-113.56 \%$, respectively for Rizatriptan. The $90 \% \mathrm{CIs}_{\text {of }} \mathrm{AUC}_{0 \rightarrow \mathrm{t}}$, $\mathrm{AUC}_{0 \rightarrow \infty}$, and $\mathrm{C}_{\max }$ values were totally within $80-125 \%$.

Conclusion: Based on a statistical analysis of the results, both formulations of Rizatriptan 10 mg, were found to be bioequivalent in terms of rate and extent of absorption under fasting conditions.

Keywords: Rizatriptan, Orally Disintegrating Strips, Pharmacokinetics, Bioequivalence, Migraine

(C) 2021 The Authors. Published by Innovare Academic Sciences Pvt Ltd. This is an open access article under the CC BY license (https://creativecommons.org/licenses/by/4.0/) DOI: https://dx.doi.org/10.22159/ijap.2021v13i5.41602. Journal homepage: https://innovareacademics.in/journals/index.php/ijap

\section{INTRODUCTION}

Migraine is a common neurologic disorder with a paroxysmal character. Lost work productivity following migraine attacks severely affects both patients and society. This condition is most prevalent during the most economically productive years of the person, with a peak at $\sim 40 \mathrm{y}$ of age. Attacks of moderate or severe headache associated with nausea, vomiting, photophobia, or phonophobia occur in $3 \%$ to $6 \%$ of males and $13 \%$ to $18 \%$ of females [1-5]. Migraine attacks can also lead to disabilities and affect the quality of relationships, social behavior, economic assets, emotional well-being, and overall health of the patients [6-8]. Thus, effective treatment of acute migraine attacks is always looked for in clinical practices for improving health-related quality of life and economic growth [9].

Rizatriptan is an anti-migraine drug belonging to the class of serotonin receptor agonist, 5-HT1. Rizatriptan is indicated for the acute treatment of migraine with or without aura in adults [10]. The 10 -mg dose was found to be more effective than the $5-\mathrm{mg}$ dose in the case of adults and pediatric patients $[10,11]$. Rizatriptan is absorbed quickly after oral administration. It is absorbed completely from the gastrointestinal tract and achieves shorter Tmax than other triptans [12]. It exhibits a favorable tolerability profile and greater patient compliance over other triptans as well [13]. However, mean oral absolute bioavailability is about $45 \%$ due to hepatic first-pass metabolism of the drug [12].

Rizatriptan is available in the form of conventional swallowable tablets and orally disintegrating tablets (ODT). The Tmax for Rizatriptan in tablet form is $1-1.5 \mathrm{~h}$ and about $1.6-2.5 \mathrm{~h}$ for ODT. The onset of the effect of Rizatriptan occurs after at least 30 min with 10 mg oral tablet [14]. The slower Tmax may be responsible for delayed onset of action associated with formulations like ODT. Further, ODT s are highly friable and fragile as they are manufactured using lyophilization or low compression technology, therefore, it is difficult to handle them during administration and transportation.

Orally disintegrating strip (ODS) is a novel dosage form that overcomes the limitations of ODT. It consists of thin, rectangular film that dissolves instantaneously when kept on the tongue without requiring the intake of water [15-18]. Additionally, these films are flexible and do not break or crumble during handling and transportation. These features make ODS, a convenient and consumer-friendly dosage form [18].

The ODS technology can therefore serve as a very useful option for delivering drugs for migraine. During migraine attacks, the patient is under huge distress and any change in the position of the head may worsen the pain and symptoms like nausea and vomiting. The easy administration and fast dissolving feature of ODS bring quick relief during acute migraine attacks and avoid the need for injectable formulations.

Considering the clinical aspects of 'migraine' and related pathologies, immediate release of medicament is a must for quick onset of action and relief. Therefore, considering various attributes of ODS technology, Rizatriptan ODS was developed to offer other beneficial and effective options to the consumers.

The main objective of the present study was to determine bioequivalence between the novel ODS containing $10 \mathrm{mg}$ Rizatriptan (test product, T) against Maxalt-MLT® (Oral Lyophilisate, $10 \mathrm{mg}$ Rizatriptan, reference product, R) under fasting conditions in healthy male volunteers. The safety and tolerability of a single oral dose of Rizatriptan ODS and Oral Lyophilisate were also monitored.

\section{MATERIALS AND METHODS}

A randomized, open-label, balanced, two-treatment, two-period, two-sequence, single-dose, crossover study was conducted. All of the subjects were randomly assigned to one of two sequences of the two formulations: ODS containing Rizatriptan $10 \mathrm{mg}$ (test product) and Oral Lyophilisate containing Rizatriptan $10 \mathrm{mg}$ (reference product). The baseline evaluations were performed before dosing.

The study protocol was approved by the Independent Ethics Committee (Ethics Committee No. ECR/112/Indt/MH/2013). The study was conducted following the Declaration of Helsinki (Ethical Principles for Biomedical Research involving Human Male Subjects, 
Brazil 2013), current ICH GCP guidelines, relevant National Laws and Regulations, ICMR (Indian Council of Medical Research) regulations, and CDSCO (Central Drugs Standards Control Organization) guidelines including the archiving of essential documents.

\section{Subjects}

A total of 59 adults, male human volunteers were screened to enroll 24 subjects for this study. A detailed explanation of the study was provided to each participant, and their written informed consent was obtained before the screening.

Inclusion criteria for recruitment of participants included subjects between the age of 18-45 y, BMI (18-25), whose physical examination was done, vital signs were within the acceptable limit, agreed to abstain from consuming any xanthine or caffeinecontaining food or beverage, grapefruit juice, alcoholic or tobacco products and cigarette for at least $48 \mathrm{~h}$ before dosing and throughout the study period and until last blood sample was withdrawn and with no evidence of any underlying disease during screening medical history and whose medical examination is performed within $21 \mathrm{~d}$ prior to commencement of study.

All subjects with Triptan-induced allergy history were excluded from the study. Subjects with evidence of or history of clinically significant cardiovascular, gastrointestinal, pulmonary, hematological, endocrine, metabolic disorder, malignancy or immunodeficiency disorder, hepatic, psychiatric, or neurological disorder were excluded. Subjects with abnormal laboratory findings, vital signs, ECG, etc. were not included. Additionally, subjects were excluded if they had received any depot injections or implants within 6 mo before the study or had consumed any medication (prescribed or over-the-counter) during 14 $\mathrm{d}$ before dosing and till the completion of the study. Subjects were excluded if had a history or evidence of drug abuse or had alcohol consumption, grapefruit juice, caffeine-containing drinks or beverages, cigarette smoking, or tobacco products intake within $48 \mathrm{~h}$ before dosing. Subjects should not have donated blood $90 \mathrm{~d}$ before administration of study medication.

Subjects were excluded if they had any surgical or medical conditions that could significantly modify the pharmacokinetics of Rizatriptan. Subjects were also excluded if they had participated in another clinical study within $90 \mathrm{~d}$ preceding the administration of study medication. Negative serological tests result for HIV, Hepatitis B, Hepatitis C, and syphilis was an essential criterion for inclusion.

Subjects were also excluded if they showed any significant illness within $4 \mathrm{w}$ before the start of the study. If systolic blood pressure was below $100 \mathrm{~mm}$ of $\mathrm{Hg}$ and above $140 \mathrm{~mm}$ of $\mathrm{Hg}$ or diastolic pressure was below $60 \mathrm{~mm}$ of $\mathrm{Hg}$ and above $90 \mathrm{~mm}$ of $\mathrm{Hg}$ or if pulse rate was below 50 per minute and above 100 per minute, in that case, subjects were excluded from the study.

\section{Study design}

This was an open-label, randomized, balanced, two-sequence, twoperiod, two-treatment, single-dose, crossover bioequivalence study. Demographic data including BMI, clinical history, physical examination (including vital signs), ECG, laboratory tests including hematology, biochemistry, serology, breath alcohol test, and urine analysis were performed during the screening. A urine screen for drugs of abuse and a breath alcohol test was done before check-in for each study period.

A total of 24 healthy, adult, normal, human male subjects were enrolled for the study. The subjects were confined within the facility at least $12 \mathrm{~h}$ before dosing until $24 \mathrm{~h}$ post-dose during each study period. Subjects were fasted for at least $10 \mathrm{~h}$ before drug administration and for $4 \mathrm{~h}$ post-dose in each study period. Subjects reported for the second period after a washout period of at least 07 d. Plasma samples of these subjects were analyzed and considered to draw a statistical conclusion.

All of the subjects were randomly assigned to one of two sequences of the two formulations: $10 \mathrm{mg}$ Rizatriptan ODS as the test drug and $10 \mathrm{mg}$ Rizatriptan Maxalt-MLT Oral Lyophilisate as the reference drug. Subjects were administered with a single oral dose of the test product or the reference product as per the randomization schedule with $240 \mathrm{ml}$ of water at ambient temperature administered immediately after disintegration of the formulation on the tongue in a sitting position during each study period. Physical examinations and vitals assessments were done at the time of check-in and checkout of each study period. The study design is summarized in fig. 1.

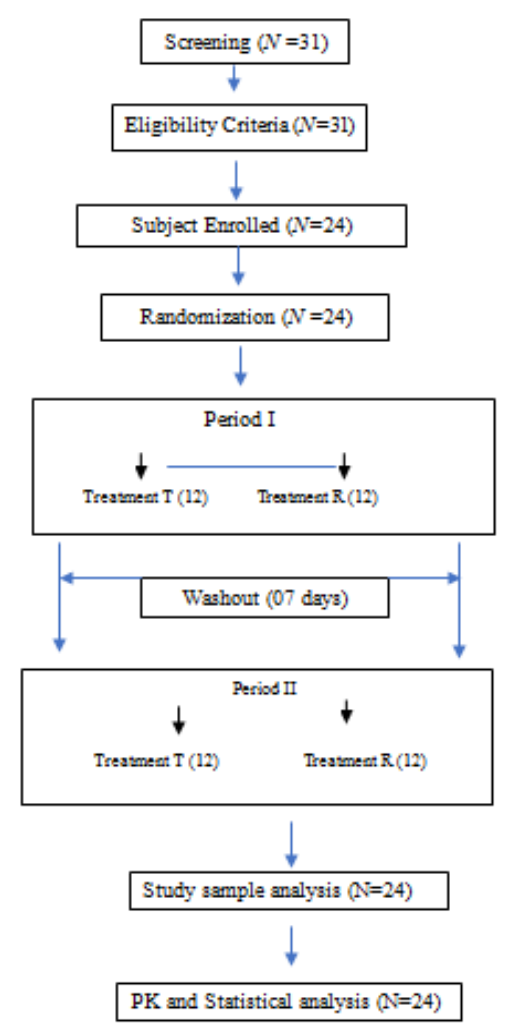

Fig. 1: Clinical study design and plan flow diagram

\section{Safety and tolerability assessments}

Vital signs (BP, pulse rate, body temperature, respiratory rate) assessments and well-being assessment were done pre-dose and at $3,6,12$, and $24 \mathrm{~h}$ post dose $\pm 45 \mathrm{~min}$ (except for pre-dose) of scheduled time in each study period.

Products studied: Test Product (Rizatriptan $10 \mathrm{mg}$ Orally Disintegrating Strip (Batch number: B00049/006 manufactured by Zim Laboratories, India) and Reference Products (Maxalt MLT $10 \mathrm{mg}$ Rizatriptan Oral Lyophilisate (Batch number: 15K8PG/1020110 manufactured by Merck Sharp and Dohme Limited, UK) were well tolerated and no adverse events were found during the conduct of the study. The laboratory values observed out of the reference range were evaluated based on clinical correlation.

\section{Pharmacokinetic assessments}

A total of 24 subjects completed the clinical phase of the study successfully. A total of 19 blood samples ( $05 \mathrm{ml}$ per sample) of each subject were collected in each study period. Blood samples were collected in pre-labelled vacutainers with $\mathrm{K}_{3}$-EDTA as an anticoagulant at pre-dose (collected within $0.5 \mathrm{hr}$ prior to dosing) and at $0.25,0.50,0.75,1.00,1.25,1.50,1.75,2.00,2.33,2.67,3.00$, $4.00,5.00,6.00,8.00,10.00,12.00,24.00 \mathrm{hr}$ post dose within $2 \mathrm{~min}$ of scheduled sampling time.

Approximately $229 \mathrm{ml}$ (19 blood samples of $05 \mathrm{ml}$ each in two periods $=190 \mathrm{ml}, 19 \mathrm{ml}$ of discarded blood, $10 \mathrm{ml}$ of blood for prestudy screening, and $10 \mathrm{ml}$ for post-study examination) of total blood was withdrawn from the subjects. The blood samples were centrifuged for five minutes under refrigeration, with the machine set at $3500 \mathrm{rpm}$, and $5{ }^{\circ} \mathrm{C} \pm 3{ }^{\circ} \mathrm{C}$. The plasma portions were transferred to polypropylene vials (pre-labeled) biological samples 
storage vials in duplicate and stored at $-20^{\circ} \mathrm{C} \pm 5^{\circ} \mathrm{C}$ in a deep freezer. Drinking water was not allowed to the subjects from 1-hour predose and 2-hours post-dose.

Subjects were provided with a standardized meal during check-in night and then at around $04.00,09.00$ and $13.00 \mathrm{~h}$ post-dose. The test and reference products were administered to the subjects in sitting positions. Subjects remained seated for the first $2 \mathrm{~h}$ postdose. The subjects refrained from any strenuous activity during the confinement period at the testing facility. All subjects were also instructed to abstain from consuming any xanthine/caffeinecontaining food or beverages, grapefruit juice or product, alcoholic products, cigarette and tobacco products for $48 \mathrm{~h}$ before first dosing until the last blood sample collection for the last study period.

Physical examination including vitals examination, wellbeing assessment, ECG, hematology, biochemical, and urine analyses was done at the end of the study. The washout period was of $07 \mathrm{~d}$ between dosing of each period.

\section{Bioanalytical method}

The plasma concentrations of Rizatriptan were determined using validated liquid chromatography coupled with tandem mass spectrometry (LC-MS/MS) technique. The analytical method validation included $500 \mu \mathrm{l}$ of plasma samples and extraction by liquid-liquid extraction method. Zolmitriptan was used as an internal standard [19].

For method validation, the lower limit of quantification was 1.040 $\mathrm{ng} / \mathrm{ml}$ for Rizatriptan. For method validation, the calibration curve range was 1.015 to $65.525 \mathrm{ng} / \mathrm{ml}$ for Rizatriptan enough to quantify the expected concentration range of drug from the subject's plasma with the proposed dose of Rizatriptan.

\section{Pharmacokinetic analyses}

The pharmacokinetic parameters were calculated by the noncompartmental method using SAS ${ }^{\circledR}$ software. The following parameters were estimated for each subject given the test and reference formulation under fasting conditions:

\section{a. $\mathrm{C}_{\max }$ and $\mathrm{T}_{\max }$}

The maximum plasma concentration $\left(\mathrm{C}_{\max }\right)$ and the time of the peak concentration $\left(\mathrm{T}_{\max }\right)$ were taken directly from the plasma concentration-time profiles of individual subjects. The units of $\mathrm{C}_{\max }$ and $T_{\max }$ are $\mathrm{ng} / \mathrm{ml}$ and hour (h) respectively. The area under the concentration-time curve was calculated by the linear trapezoidal rule from measured data points from the time of administration until the time of the last quantifiable concentration.

\section{b. $\mathrm{AUC}_{\mathbf{0} \rightarrow \infty}$}

The area under the concentration-time curve in $\mathrm{ng} / \mathrm{ml}$ was estimated by the linear trapezoidal rule $\left(\mathrm{AUC}_{0 \rightarrow \mathrm{t}}\right)$ and extrapolated to infinity $\left(\mathrm{AUC}_{0 \rightarrow \infty}\right)$. The extrapolation was performed by dividing the estimated last measurable plasma concentration by the terminal rate constant $\mathrm{Ke} 1$. The $\mathrm{AUC}_{0 \rightarrow \infty}$ was the sum of the estimated and extrapolated parts.

\section{c. $K_{e 1}$}

The elimination rate constant $\left(\mathrm{K}_{\mathrm{e} 1}\right)$ was calculated as per hour, as the negative slope of the log-linear terminal portion of the plasma concentration versus time curve using the linear regression. Minimums of three concentrations were considered; starting from $\mathrm{C}_{t}$ to $\mathrm{C}_{\max }$ and the best-fitted line with maximum $\mathrm{r}^{2}$ was selected.

\section{d. $\mathbf{t}_{1 / 2}$}

The terminal half-life $\left(t_{1 / 2}\right)$ was estimated (in hours) from the slope (terminal rate constant Ke1) of the terminal phase of the semilogarithmic plot of the plasma concentration curve $\left(\mathrm{t}_{1 / 2}=0.693 / \mathrm{K}_{\mathrm{e} 1}\right)$. The actual time of blood sampling was used for these calculations. Concentration values below the limit of quantification (BLQ) were considered as 0.000 for pharmacokinetic and statistical calculations. It was assumed that the terminal elimination phase was reached within the sampling period. The interval used for the determination of the elimination rate constant is also reported.

\section{Statistical analyses}

The pharmacokinetic parameters $\mathrm{C}_{\max }, \mathrm{AUC}_{0 \rightarrow \mathrm{t}}$ and $\mathrm{AUC}_{0 \rightarrow \infty}$ were considered as primary variables for the bioequivalence analysis. Bioequivalence between the two formulations was determined by calculating $90 \%$ confidence intervals $(90 \% \mathrm{CI})$ for the ratio of $\mathrm{C}_{\max }$, $\mathrm{AUC}_{0 \rightarrow \mathrm{t}}$, and $\mathrm{AUC}_{0 \rightarrow \infty}$ values for the test and reference formulations, using logarithmically transformed data. ANOVA was used to assess product, group, and period effects. The statistical analysis was performed using SAS ${ }^{\circledR}$ software. The plasma concentrations at each sampling time point were noted for each subject and product together with its descriptive statistics. All the below the level of quantification (BLQ) values were considered as zero for the computation of pharmacokinetic parameters and statistical calculations. The mean plasma concentrations for all the subjects, concentrations vs time profiles for each product were represented on both the scales i.e., on the untransformed and log-transformed data.

The $90 \%$ confidence interval was constructed for the difference (Test-Reference) of least-square means of the log-transformed $\mathrm{Cmax}, \mathrm{AUC}_{0 \rightarrow \mathrm{t}}$, and $\mathrm{AUC}_{0 \rightarrow \infty}$. The antilog (or exponential) of these limits gives the $90 \%$ confidence interval for the ratio of geometric least-square means of the test and reference formulations.

The geometric least square mean ratios of the test and reference product of Rizatriptan and its $90 \%$ confidence interval on the logtransformed pharmacokinetic parameters-Cmax, $\mathrm{AUC}_{0 \rightarrow \mathrm{t}}$, and $\mathrm{AUC}_{0 \rightarrow \infty}$ were computed and bioequivalence was considered if the confidence interval lies within the acceptable, range of $80 \%-125 \%$ for logtransformed Cmax, $\mathrm{AUC}_{0 \rightarrow \mathrm{t}}$ and $\mathrm{AUC}_{0 \rightarrow \infty}$.

\section{RESULTS AND DISCUSSION}

\section{Demographic characteristics}

For this study, in total, 24 healthy, adult, male volunteers were enrolled, participated, and randomized into experimental groups. The demographic characteristics of all 24 subjects are summarized in table 1.

Table 1: Demographic characteristics of all 24 subjects who participated in the study

\begin{tabular}{lllll}
\hline & Age (years) & Weight $(\mathbf{k g})$ & Height $(\mathbf{m})$ & BMI $_{\left(\mathbf{k g} / \mathbf{m}^{2}\right)}$ \\
\hline Mean & 31.042 & 66.175 & 1.705 & 22.742 \\
Minimum & 21.000 & 51.700 & 1.610 & 18.318 \\
Maximum & 41.000 & 75.400 & 1.770 & 24.483 \\
SD & 5.614 & 6.924 & 0.043 & 1.989 \\
\hline
\end{tabular}

All 24 subjects completed the study as planned. Subjects were continuously monitored and periodically questioned for any adverse events throughout the study. The tolerability of both Rizatriptan medications was good.

No serious adverse reactions, non-compliance to protocol, or withdrawal from the study were observed. No clinically significant findings were detected upon physical examination, including changes in vital signs, electrocardiography, or clinical laboratory evaluations.

\section{Pharmacokinetics}

The data of all 24 subjects who completed the whole study were used to accomplish pharmacokinetic and statistical analysis. The drug concentration of Rizatriptan in plasma for each subject, each 
sampling time, and each product was reported. The mean pharmacokinetic parameters estimated for all the subjects for Rizatriptan for both the Test and Reference products are shown in table 2 .

The pharmacokinetic parameters show close mean values, with only marginal differences between the test and reference products. With both the formulations, Rizatriptan appeared early in plasma, in most cases at around after $1 \mathrm{~h}$. The peak was reached on average at $1.00 \mathrm{~h}$ $(25.512 \pm 9.093)-1.25 \mathrm{~h}(25.674 \pm 10.349)$ with the test. The reference product exhibited a peak at $1.00 \mathrm{~h}(27.109 \pm 9.944)$ at $1.25 \mathrm{~h}$ $(25.428 \pm 10.455)$. A decrease in concentrations was detectable in most cases by $24 \mathrm{~h}$.

The mean plasma Rizatriptan concentration versus time profiles after administration of Rizatriptan ODS and reference product are shown in fig. 2. These were superimposable for the two formulations. In addition, the median Tmax and the mean values of Cmax, $\mathrm{AUC}_{0 \rightarrow \mathrm{t}}$ and $\mathrm{AUC}_{0 \rightarrow \infty}, \mathrm{t}_{1 / 2}$, and $\mathrm{CL} / \mathrm{F}$ of Rizatriptan were also comparable between the two formulations, as presented in table 2 .

Table 2: Plasma pharmacokinetic parameters with test product (T) and reference product (R)

\begin{tabular}{|c|c|c|c|c|c|c|c|}
\hline Formulations & & $\begin{array}{l}\text { Cmax } \\
(\mathrm{ng} / \mathrm{ml})\end{array}$ & $\begin{array}{l}\mathrm{AUC}_{0 \rightarrow \mathrm{t}} \\
(\mathrm{ng} / \mathrm{ml} \times \mathrm{h})\end{array}$ & $\begin{array}{l}\text { AUC }_{0 \rightarrow \infty} \\
(\mathrm{ng} / \mathrm{ml} \times \mathrm{h})\end{array}$ & $\begin{array}{l}\text { Tmax } \\
\text { (h) }\end{array}$ & $\begin{array}{l}\text { Ke1 } \\
\text { (per hour) }\end{array}$ & $\begin{array}{l}t_{1 / 2} \\
(h)\end{array}$ \\
\hline \multirow[t]{2}{*}{ Test Product (T) } & Arithmetic Mean & 30.330 & 102.859 & 107.323 & 1.177 & 0.402 & 1.820 \\
\hline & SD & 8.599 & 26.634 & 27.319 & 0.782 & 0.098 & 0.422 \\
\hline Reference Product & Arithmetic Mean & 30.691 & 100.319 & 105.566 & 1.073 & 0.373 & 1.932 \\
\hline$(\mathrm{R})$ & SD & 11.871 & 31.654 & 32.799 & 0.554 & 0.085 & 0.371 \\
\hline \% Ratio (T/R) & Arithmetic Mean & 98.82 & 102.53 & 101.66 & - & - & - \\
\hline
\end{tabular}

$(\mathrm{N}=24)$

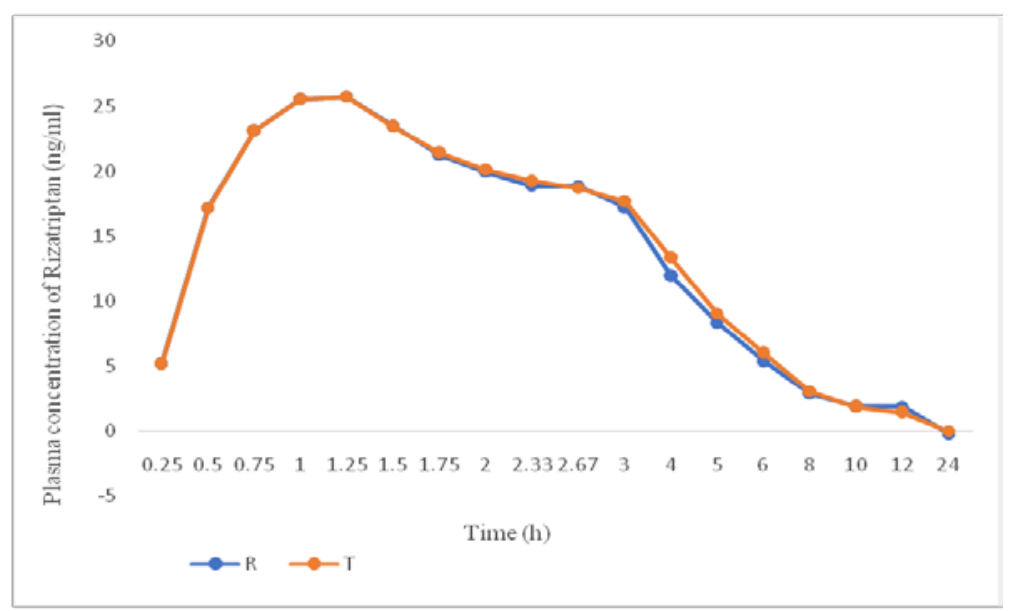

Fig. 2: Mean plasma concentration graph for test $(T)$ and reference $(R)$ products of rizatriptan

For Rizatriptan, the geometric mean and 90\% confidence interval $(90 \% \mathrm{CI})$ based on least-squares mean obtained from ANOVA for the pharmacokinetic parameters $\mathrm{C}_{\max }, \quad \mathrm{AUC}_{0 \rightarrow \mathrm{t}}$, and $\mathrm{AUC}_{0 \rightarrow \infty}$ are summarized in table 3 .

Table 3: Geometric means and $90 \%$ confidence Interval for Rizatriptan for all the subjects ( $=24),{ }^{*}$ Geometric mean was taken as the antilog (exponential) of the least square mean of the log- transformed data

\begin{tabular}{lllll}
\hline Pharmacokinetic & \multicolumn{2}{l}{${ }^{*}$ Geometric mean } & \% Ratio & 90 \% Confidence Interval for Log-transformed data \\
\cline { 2 - 5 } parameters & Test (T) & Reference (R) & T/R & Lower limit \\
\hline $\mathrm{AUC}_{0 \rightarrow \infty}(\mathrm{ng} / \mathrm{ml} \mathrm{x} \mathrm{h})$ & 104.174 & 101.678 & 102.46 & 96.24 \\
$\mathrm{AUC}_{0 \rightarrow \mathrm{t}}(\mathrm{ng} / \mathrm{ml} \mathrm{x} \mathrm{h)}$ & 99.741 & 96.473 & 103.39 & 96.91 \\
$\mathrm{Cmax}(\mathrm{ng} / \mathrm{ml})$ & 29.178 & 28.803 & 100.30 & 90.37 \\
\hline
\end{tabular}

The ANOVA analysis revealed, significant subject (sequence) effect for Log transformed

Cmax, $\mathrm{AUC}_{0 \rightarrow \mathrm{t}}$, and $\mathrm{AUC}_{0 \rightarrow \infty}$, significant period effect for $\mathrm{Log}$ transformed $\mathrm{AUC}_{0 \rightarrow \mathrm{t}}$ and $\mathrm{AUC}_{0 \rightarrow \infty}$; the non-significant period effect was observed for Log transformed Cmax. The non-significant treatment effect was also observed for Log transformed Cmax, $\mathrm{AUC}_{0 \rightarrow \mathrm{t}}$, and $\mathrm{AUC}_{0 \rightarrow \infty}$ (table 3, 4, and 5).

Furthermore, it was evident from table 3, table 4, and table 5 that both test and reference products fall entirely within the conventional bioequivalence range of 0.8-1.25.

During the clinical practice, voluntary and quick swallowing of an oral dosage form by the patient is a major concern especially with geriatric, pediatric, bedridden, mentally challenged individuals and patients with neuromuscular disorders like Parkinson's disease, multiple sclerosis, migraine, etc. where a patient may find it very difficult to swallow the medicine. Therefore, the physicians and the patients are always in quest of other alternatives in comparison to existing oral dosage forms [20,21].

Orally Disintegrating Strip (ODS) is a comparatively newer dosage form that is prepared using hydrophilic polymers that rapidly dissolve on the tongue. The availability of a larger surface area in the oral cavity leads to rapid disintegration and dissolution. The clinical condition of the patient during 'migraine' attacks demands quick onset of action of the drug. During a migraine attack, the patient is unable to swallow anything. In such cases, ODS offers an alternate, fast-acting option where difficulty in swallowing is circumvented $[20,21]$. 
Table 4: Statistical analysis data for Ln transformed parameters of Rizatriptan ( $n=24)$

\begin{tabular}{lll}
\hline & Cmax & AUC0-t \\
\hline ANOVA p-value & & $<.0001$ \\
Subject (Seq) & 0.0292 & 0.0126 \\
Period & 0.5448 & 0.3864 \\
Treatment & 0.8476 & 99.741 \\
Geometric Least Square Mean for Test Product (T) & 29.178 & 96.473 \\
Geometric Least Square Mean for Reference Product (R) & 28.803 & 0.0125 \\
Ratio of Geometric Least Square Mean (\%) (T/R) & 100.30 & 103.39 \\
$90 \%$ Confidence Interval (T vs R) Lower Limit & 90.37 & 96.91 \\
$90 \%$ Confidence Interval (T vs R) Upper Limit & 113.56 & 110.30 \\
Intra Subject variability (\%) & 23.35 & 13.11 \\
Power & 90.25 & 100.00 \\
\hline
\end{tabular}

Table 5: Descriptive statistics for untransformed parameters of Rizatriptan $(n=24)$

\begin{tabular}{|c|c|c|c|c|}
\hline Measures & Cmax (ng/ml) & $\operatorname{AUC}_{0 \rightarrow \mathrm{t}}(\mathrm{ng} / \mathrm{ml} \times \mathrm{h})$ & $\mathrm{AUC}_{0 \rightarrow \infty}(\mathrm{ng} / \mathrm{ml} \times \mathrm{h})$ & $\operatorname{Tmax}(\mathrm{h})$ \\
\hline \multicolumn{5}{|c|}{ Test Product } \\
\hline $\mathrm{N}$ & 24 & 24 & 24 & 24 \\
\hline Mean & 30.330 & 102.859 & 107.323 & 1.177 \\
\hline SD & 8.599 & 26.633 & 27.319 & 0.782 \\
\hline $\mathrm{CV}(\%)$ & 28.35 & 25.89 & 25.46 & 66.42 \\
\hline \multicolumn{5}{|c|}{ Reference Product } \\
\hline $\mathrm{N}$ & 24 & 24 & 24 & 24 \\
\hline Mean & 30.691 & 100.319 & 105.566 & 1.073 \\
\hline SD & 11.871 & 31.654 & 32.799 & 0.554 \\
\hline CV (\%) & 38.68 & 31.55 & 31.07 & 51.64 \\
\hline
\end{tabular}

During the present study, Rizatriptan ODS was developed to provide a suitable dosage form to achieve quick onset of action in case of migraine attacks. The results of the randomized, open-label, balanced, two-treatment, two-period, two-sequence, single-dose, crossover bioequivalence study of Rizatriptan 10 mg Orally Disintegrating Strips (ODS) are demonstrated here. The study was conducted on 24 healthy male volunteers under fasting conditions. The objectives of the study also included pharmacokinetics, bioequivalence check, evaluation of safety, efficacy, and tolerability of Rizatriptan ODS.

The authors evaluated the pharmacokinetics of $10 \mathrm{mg}$ Rizatriptan when administered to healthy subjects as a new ODS formulation or as a reference product. This study indicated that $\mathrm{Cmax}, \mathrm{AUC}_{0 \rightarrow \infty}$, and $\mathrm{AUC}_{0 \rightarrow \mathrm{t}}$ was comparable for the ODS (test) and Maxalt-MLT (reference) formulations. The geometric mean ratios (\%) for $\mathrm{Cmax}$, $\mathrm{AUC}_{0 \rightarrow \mathrm{t}}$, and $\mathrm{AUC}_{0 \rightarrow \infty}$ were $100.30,103.39$, and 102.46 respectively. The $90 \%$ CIs for the test and reference products were within the acceptable, conventional bioequivalence range of 80\%-125 \%. Also, pharmacokinetic parameters including Tmax, $\mathrm{AUC}_{0 \rightarrow \infty}, \mathrm{t}_{1 / 2}$, and $\mathrm{K}_{\mathrm{el}}$ of Rizatriptan were comparable between both formulations.

Furthermore, the mean plasma concentration-time profiles were similar for the test and reference formulations of Rizatriptan from pre-dose $(0 \mathrm{hr})$ to $24 \mathrm{~h}$ after dosing. Based on these results, the bioavailability of the Rizatriptan ODS formulation can be concluded to be comparable to that of the marketed reference formulation.

This study was conducted as a two-way crossover design, which is a generally accepted method for bioequivalence studies. With the blood-sampling time points set from pre-dose to $24 \mathrm{~h}$ after dosing, we could fully illustrate the Rizatriptan disposition and absorption phases. Additionally, the 7-days washout period implemented between the two study periods was considered sufficient as it was more than five times the $t_{1 / 2}$ of Rizatriptan. No carryover effect was found in the second phase of the study.

The pharmacokinetic properties of Rizatriptan presented in this study were consistent with those reported previously [22]. A similar drug delivery approach was evaluated with a analogous antimigraine drug molecule Eletriptan hydrobromide and was found to be successful [23]. It had been described that, in the case of Rizatriptan, Tmax is negatively influenced by food. The present study was carried out in healthy adult male volunteers, under fasting conditions to avoid the influence of food and other conditions which may likely interfere with the pharmacokinetics. The findings of the study indicate that the two formulations of Rizatriptan used are likely to exhibit similar bioavailability.

In the context of compliance improvement, efficacy, safety, and convenience are important factors to be considered in clinical practices. From the observations of the study, it can be corroborated that the ODS and reference formulation had comparable pharmacokinetics, safety, and tolerability profiles and no clinically significant changes from the baseline were observed after dosing.

The ODS formulation has advantages over conventional tablet formulations because it dissolves rapidly in the oral cavity, without the need to drink water. The ODS formulation could therefore be easier to use, particularly for elderly patients and children. It should be considered as a novel, non-obstructive route of drug delivery [24].

So, the findings of this study suggest that the ODS and reference products containing $10 \mathrm{mg}$ Rizatriptan revealed comparable plasma level-time profiles, and the $90 \%$ CIs of the geometric mean ratio indicated bioequivalence. Therefore, the novel Rizatriptan ODS has the potential to provide a more convenient alternative over the available marketed products for timely relief to migraine patients.

Limitations of the present study: The present study was conducted with 24 healthy volunteers. It is suggested that further trials are needed in larger population of healthy volunteers and patients of different age groups as well. Orally Disintegrating Strip formulation technology is mainly focused on pediatric and elderly patients. In case of geriatric population, age-related concomitant disease conditions and medications are likely to affect action of Rizatriptan. Therefore, studies should be performed in large groups of elderly patients with concomitant ailments, pregnant women and adult (male, female) patients. The present study was carried out in healthy adult male volunteers, under fasting conditions. Thus, additional studies are needed to rule out the possibility of influence of food composition and frequency on the pharmacokinetic profile of the drug. Attempts should also focus towards use of Rizatriptan ODS for management of chronic migraine attacks.

\section{CONCLUSION}

The Orally Disintegrating Strips containing Rizatriptan $10 \mathrm{mg}$, were well absorbed after oral administration and exhibited satisfactory pharmacokinetic, safety, and tolerability profiles. Hence, it is concluded that the novel product i.e., Rizatriptan $10 \mathrm{mg}$ Orally 
Disintegrating Strip is bioequivalent to the established product (Maxalt-MLT, $10 \mathrm{mg}$ Oral Lyophilisate Rizatriptan) in terms of rate and extent of absorption under fasting conditions.

This ODS containing Rizatriptan (10 mg), offers both the physicians and patients an effective, convenient, and attractive option for the treatment of migraine. The effortless way of administration of Rizatriptan ODS without the intake of water would be certainly very helpful for patients experiencing difficulty in swallowing or nausea during their migraine attacks, thus improving patient compliance.

\section{ACKNOWLEDGEMENT}

The authors acknowledge the timely help received from all staff members of Zim Laboratories and BioSRL during this project.

\section{FUNDING}

Nil

\section{AUTHORS CONTRIBUTIONS}

All authors have contributed equally.

\section{CONFLICT OF INTERESTS}

The authors report no conflicts of interest.

\section{REFERENCES}

1. Staffa JA, Lipton RB, Stewart WE. The epidemiology of migraine headache. Rev Contemp Pharmacother 1994;5:241-52.

2. Stewart WF, Shechter A, Rasmussen BK. Migraine prevalence: a review of population-based studies. Neurology 1994;44(Suppl 4):17-23.

3. Hu XH, Markson LE, Lipton RB. Burden of migraine in the United States: disability and economic costs. Arch Intern Med 1999;159:813-8.

4. Lipton RB, Stewart WF, Von Korff M. The burden of migraine: a review of cost to society. Pharmacoeconomics 1994;6:215-21.

5. Solomon GD, Price KL. The burden of migraine: a review of its socio-economic impact. Pharmacoeconomics 1997;11(Suppl 1):1-10.

6. Clarke CE, MacMillan L, Sondhi S. Economic and social impact of migraine. QJM 1996;89:77-84.

7. Edmeads J, Findlay H, Tugwell P. Impact of migraine and tension-type headache on life-style, consulting behavior, and medication use: a canadian population survey. Can J Neurol Sci 1993;20:131-7.

8. Arne May. International Encyclopedia of Public Health: Migraine. $2^{\text {nd }}$ edition: Academic Press; 2008. p. 458-62.
9. Jhingran P, Cady RK, Rubino J. Improvements in health-related quality of life with sumatriptan treatment for migraine. J Fam Pract 1996;42:36-42.

10. Paul L McCormack, Rachel H Foster. Rizatriptan: a pharmacoeconomic review of its use in the acute treatment of migraine. Pharmacoeconomics 2005;23:1283-98.

11. Carl GH Dahlof, Alan M Rapoport, Fred D Sheftell. Rizatriptan in the treatment of migraine. Clin Ther 1999;21:1823-36.

12. MAXALT-MLT $®$ orally disintegrating tablets; product label package insert (Merck and Co.). Available from: https://www.accessdata.fda.gov/drugsatfda_docs/label/2010/ 020864s 013lbl.pdf. [Last accessed on $10 \mathrm{Feb} 2021$ ]

13. Lainez MJA. Rizatriptan in the treatment of migraine. Neuropsychiatr Dis Treat 2006;2:247-59.

14. Teall J, Tuchman M, Cutler N. Rizatriptan (MAXALT) for the acute treatment of migraine and migraine recurrence: a placebo-controlled, outpatient study. Headache: J Head Face Pain 1998;38:281-7.

15. Dixit RP, Puthli SP. Oral strip technology: overview and future potential. J Controlled Release 2009;139:94-107.

16. Hoffmann EM, Breitenbach A, Breitkreutz J. Advances in orodispersible films for drug delivery. Expert Opin Drug Delivery 2011;8:299-316.

17. Hariharan M, Bogue A. Orally dissolving film strips (ODFS): the final evolution of orally dissolving dosage forms. Drug Delivery Technol 2009;9:24-9.

18. Dahiya M, Saha S, Shahiwala AF. A review on mouth dissolving films. Curr Drug Delivery 2009;6:469-76.

19. Velusamy S, Masimukkub VM, Chereddy S. Bioanalytical method development and validation of rizatriptan in human plasma using LC-MS/MS method. Int J Chem Anal Sci 2013;4:108-14.

20. Kulkarni S, Lodhe V. Review on: alternatives to large dosage forms for ease of swallowing. J Drug Delivery Sci Technol 2020;57:1-9.

21. Irfan M, Rabel S, Bukhtar Q. Orally disintegrating films: a modern expansion in drug delivery system. Saudi Pharm J 2016;10:537-46.

22. Choksi A, Vaishya R, Inavolu R, Potta T. Intranasal spray formulation containing rizatriptan benzoate for the treatment of migraine. Int J Pharm 2019;571:118702.

23. K Pallavi, T Pallavi. Formulation and evaluation of fast dissolving films of eletriptan hydrobromide. Int J Curr Pharm Res 2017;9:59-63.

24. Tiwari RR, Umashankar MS, Damodharan N. Recent update on oral films: a bench to market potential. Int J Appl Pharma 2018; 10:27-33. 